\title{
Finite Element Analysis and Preliminary Dynamic Tests of Laboratory Bridge Model
}

\author{
Peiyao XU a, Yuan TANG ${ }^{\text {a }}$, Yexin $\mathrm{HU}^{\mathrm{a}}$ and Binbin LI ${ }^{\mathrm{a}, 1}$ \\ a ZJU-UIUC Institute, Zhejiang University, China
}

\begin{abstract}
A preliminary dynamic test of a two-span continuous girder bridge is reported in this paper, including the design specifications, the numerical model, and the modal identification result. This laboratory bridge is made of aluminum plates and connected via bolts. The finite element method is applied to build a numerical model of the bridge to aid the design and test plan. Several ambient vibration tests are conducted to extract the modal parameters, e.g., modal frequencies, damping ratios, and mode shapes, of the constructed bridge, and the Bayesian FFT algorithm is used for modal identification. We compare the identified results with those predicted by the finite element model and vary the magnitude of load to investigate its potential influence on the modal parameters. Damage cases by loosening structure members are also considered, and significant changes are observed in modal frequencies. The constructed model will be used as a benchmark for damage identification, model updating, and condition assessment, etc.
\end{abstract}

Keywords. Benchmark model, ambient vibration test, bayesian $\mathrm{fft}$, damage detection

\section{Introduction}

The role of civil engineering is essential to national infrastructure construction and economic development. Ensuring that any potential damage during the service period of the infrastructure can be detected and maintained in a timely manner is also a major crucial problem [1]. Under these circumstances, the application of modal recognition and analysis technology in the civil engineering field is of great importance. Operational modal analysis (OMA) is a method to obtain data information based on the output signal processing of large structures in the operation state [2]. Compared with the traditional input-output signal method requiring extra-human excitation, the OMA method is more suitable in the real situation [3]. In this paper, a simplified structure of the Dongying Yellow River Highway Bridge is constructed in both theoretical finite element analysis and experimental practice. Dynamic tests are processed and modal parameters like frequencies, damping ratios, and mode shapes of the experimental model are analyzed. Effects of external wind stimulation and preliminary damage identification of structure are discussed based on the test results. 


\section{Bayesian FFT Algorithm}

In operational modal analysis, because of unknown external excitation, it is usually regarded as a stationary random process and the modal parameters involved have larger uncertainty [2]. To deal with this problem, Bayesian Operational Modal Analysis (OMA) methods were put forward, which transforms the modal identification problem into a posterior probability estimate and achieves the measurement of uncertainty while determining the modal parameters at the same time [4]. The Bayesian FFT algorithm balances the robustness and computational efficiency in modeling hypothesis and can be better applied to modal parameter identification of bridge structures [5].

\section{Theoretical Analysis Using Finite Element Model}

\subsection{Background Information and Environmental Constraint}

Dongying Yellow River Highway Bridge is a prestressed concrete rigid frame and continuous composite girder bridge with a total length of $2743.1 \mathrm{~m}$, and the main part is $852.0 \mathrm{~m}$. The structure is characterized by continuous beam pier consolidation, which not only keeps the advantages of continuous beam running smoothly without expansion joints but also gets rid of support and conversion system as T type rigid frame.

\subsection{Finite Element Model Design}

\subsubsection{Constraints}

Elements in the main part are set to be coupled in all directions with each other and only the joints at two ends are set to have free movement in a parallel direction with the columns. Columns are set fixed to the ground without consideration of soil movement. Part of the APDL command flow is shown as below in the figure 1:

$c p, 1, u y, 21,1800$ - cp, next, uz, 21, 1800
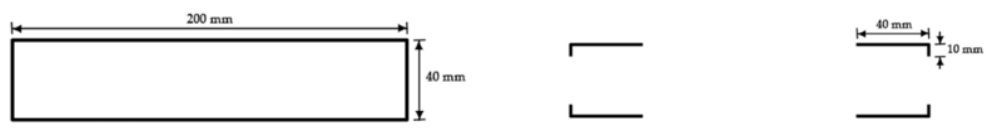

Figure 1. Designed Section of Connectional Part (Left) and Main Bridge (Right).

\subsubsection{Element and Material Selection}

Based on Timoshenko girder theory, Beam 188 element preserves its original plane cross section from distortion and considers the effect of shear deformation, thus it is appropriate to be used to analyze relatively slender girder structure in this model. Point mass is simulated using Mass 21 element. Material used is 6063-t5 Aluminum alloy with density of $2710 \mathrm{~kg} / \mathrm{m}^{3}$, elastic modulus of $69 \mathrm{GPa}$, and Poisson ratio of 0.33 . Part of the APDL command flow is shown as below:

et,1,beam188 - r,1 - et,2,mass 21 - r,2,0,0,1,0,0 - mp,ex, 1,6.89e10 - mp,dens, 1,2.7e3 - mp,prxy,1,0.33 - mat,1 - secnum, 1 - *do,i,1,50 - e,i,i+1 - *enddo - type, 2 - real,2 E,426 


\subsection{Static and Modal Analysis Result}

\subsubsection{Static Analysis}

Under the static condition, each joint connecting the column and the girder has a vertical downward displacement of $0.374 \mathrm{~mm}$, while the displacement at joints in the middle is $7.823 \mathrm{~mm}$, as shown in figure 2 . The calculated ratio of maximum deflection is 0.0037 , which meets well with the observed relationship in the reality.

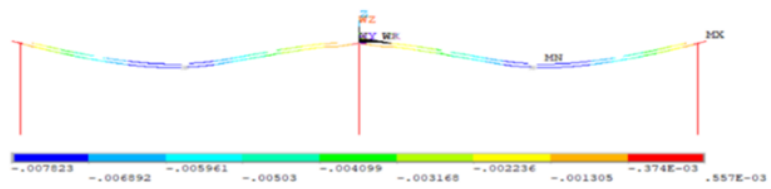

Figure 2. Z-Component of Displacement under Static Condition.

\subsubsection{Modal Analysis}

In the modal analysis, the frequency and mode shapes of different order are concluded and shown in table 1 . Both symmetry and anti-symmetry shapes of first-order vertical, torsional, and second-order vertical are shown in figure 3.

Table 1. Modal Parameters in Finite Element Model Analysis.

\begin{tabular}{llllll}
\hline Modes Order & 1 & 2 & 3 & 4 & 5 \\
\hline Frequency & 5.7865 & 5.8878 & 14.421 & 14.498 & 23.873 \\
\hline \multirow{2}{*}{ Mode Shape } & $\begin{array}{l}\text { First Order } \\
\text { Vertical }\end{array}$ & $\begin{array}{l}\text { First Order } \\
\text { Vertical }\end{array}$ & $\begin{array}{l}\text { First Order } \\
\text { Torsional }\end{array}$ & $\begin{array}{l}\text { First Order } \\
\text { Torsional }\end{array}$ & $\begin{array}{l}\text { Second-Order } \\
\text { Vertical }\end{array}$ \\
\hline & & & &
\end{tabular}

Figure 3. Structure Response in Modal Analysis of the Finite Element Model.

\section{Model Construction and Experiment Design}

\subsection{Experiment Model Construction}

The model is approximately scaled down according to the real bridge. The material, model structure, and constraints settlement are designed as indicated in the theoretical model. 6063-t5 Aluminium is used as the main building material.

The bridge model is supported by 6 fixed columns with a cross-section of $60 \mathrm{~mm} \times 60 \mathrm{~mm}$ and a thickness of $6 \mathrm{~mm}$. Connection beams are $40 \mathrm{~mm} \times 200 \mathrm{~mm} \times 2 \mathrm{~mm}$ pipes. The connections at the middle column adopt a rigid connection while both ends are connected by the pulley (figure 4).

The main beam part is a square shape made of 4 angle profiles with two sides of 
$40 \mathrm{~mm} \times 10 \mathrm{~mm}$, length of $425 \mathrm{~mm}$, and thickness of $2 \mathrm{~mm}$. Each angle profile is connected by a $200 \mathrm{~mm} \times 40 \mathrm{~mm}, 1 \mathrm{~mm}$ thick rectangular sheet to distribute the force to both sides of the beam. However, due to the large span of the model, beam is easy to sag because of self-weight. Therefore, U-shaped profiles are used between the angle profiles. In addition, a certain extent pre-camber of the bridge is set by setting the connections between angle profiles at the bottom close and tight, while keeping connections at the top with small interspaces between them. As a result, the upper part of the beam is slightly protuberant (figure 5) to offset the deflection of the beam structure due to the gravity force.

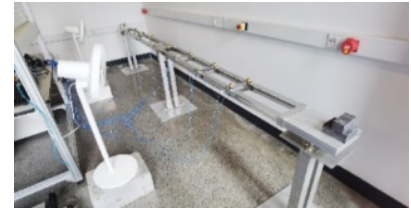

Figure 4. The Bridge Model.

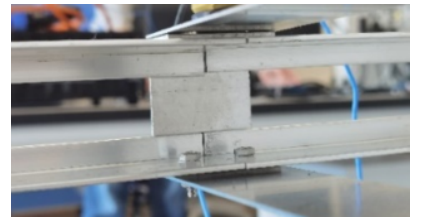

Figure 5. The Design of Pre-camber.

\subsection{Experiment Design and Process}

In all experiments, lead blocks with one kilogram each were set on the middle points of two spans. The mass put on the structure can increase the self-weight and thus reduce the vibration frequencies to better simulate the real cases. To identify basic modal properties, a reference group was set with no wind load. Three levels of winds were applied respectively to study the influence of typical ambient excitation. To further study damage detection, three groups with one bolt, two bolts, and one U-shaped slot removed respectively would be conducted. All damages are created at the middle span.

\section{Analysis of Structure Behavior Based on Modal Parameters}

\subsection{Modal Response of Structure}

Using Bayesian OMA, the frequency domain graph and mode shapes can be obtained by MATLAB. The relationship between the time domain and frequency domain can be built through the Fast Fourier Transform, then the Singular Value (SV) spectrum and Power Spectrum Density (PSD) spectrum are gained [6], as shown in figure 6.
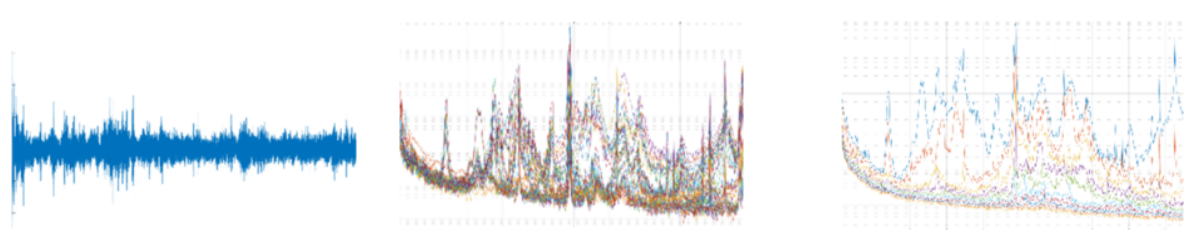

Figure 6. Time Domain (Left), PSD Spectrum (Middle), and SV Spectrum (Right) with No Wind.

Mode shapes and frequency results are summarized in figure 7 and table 2 . Symmetric and anti-symmetric first-order vertical and torsional modes are found with two spans vibrating in the same or different directions. It should be noted that the amplitudes of vibration of two spans are not the same. This error is mainly due to the 
fact that the two spans of the structure could not be assembled in the same way, therefore their stiffness may be different. Nevertheless, the error is within a reasonable range so that analysis of the result still has reliability. Modes in higher-order have been detected as well, in which vertical and torsional vibrations start coupling with each other and provide complicated mode shapes.

Table 2. Modal Parameters in Experimental Model Analysis

\begin{tabular}{llllll}
\hline Modes & Frequency & Mode Shape & Modes & Frequency & Mode Shape \\
\hline 1 & 6.78 & First Order Vertical & 4 & 14.4 & First Order Torsional \\
2 & 6.95 & First Order Vertical & 5 & 16.9 & First Order Torsional \\
3 & 11.1 & First Order Horizontal & 6 & 25.8 & Second-Order Vertical \\
\hline
\end{tabular}
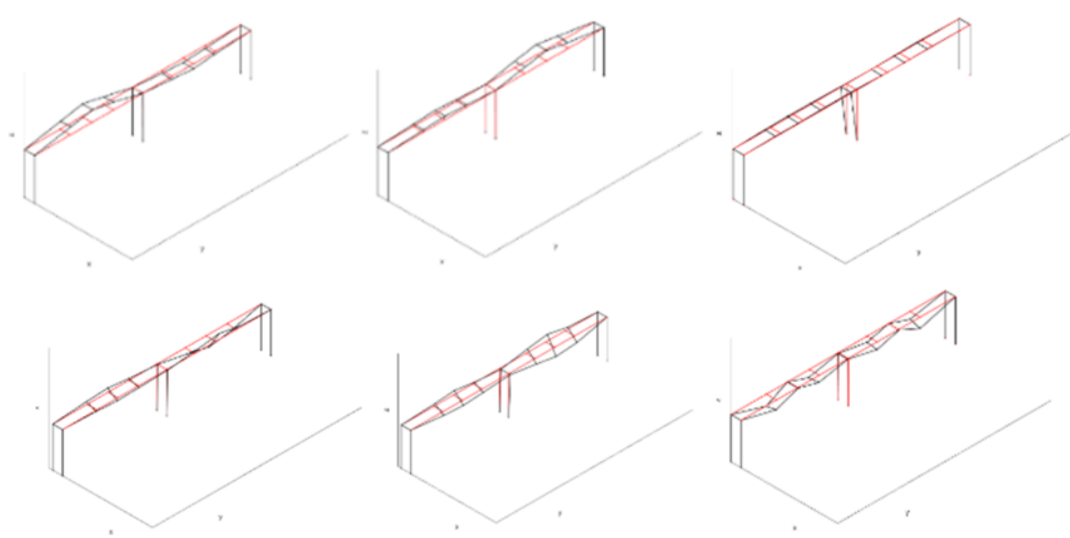

Figure 7. Structure Response of in Modal Analysis of Experimental Model.

\subsection{Modal Behavior under Different Loading}

Under different levels of wind, it is concluded that the frequency basically does not change, which meets the expectations. The frequency is an intrinsic structure property, having a positive relationship with structural stiffness and a negative one with mass [7]. The damping ratio has a larger relative standard deviation, but the results are within a reasonable range of fluctuation. It is observed to be amplitude-dependent, being larger as the wind level increases as expected [8]. The results are summarized in tables 3-4.

Table 3. Frequency Results under Different Wind Loading.

\begin{tabular}{llllllll}
\hline $\begin{array}{l}\text { Wind Load } \\
\text { Level }\end{array}$ & $\begin{array}{l}\text { Symmetry } \\
\text { First Order } \\
\text { Vertical }\end{array}$ & $\begin{array}{l}\text { Anti-symmetry } \\
\text { First Order } \\
\text { Vertical }\end{array}$ & Horizontal & $\begin{array}{l}\text { Symmetry } \\
\text { First Order } \\
\text { Torsional }\end{array}$ & $\begin{array}{l}\text { Anti-symmetry } \\
\text { First Order } \\
\text { Torsional }\end{array}$ & $\begin{array}{l}\text { Second-Order } \\
\text { Vertical }\end{array}$ \\
\hline left & right & $(\mathrm{Hz})$ & $(\mathrm{Hz})$ & $(\mathrm{Hz})$ & $(\mathrm{Hz})$ & $(\mathrm{Hz})$ & $(\mathrm{Hz})$ \\
\hline 0 & 0 & 6.75 & 6.94 & 11.1 & 14.4 & 16.9 & 25.8 \\
1 & 1 & 6.69 & 6.91 & 11.1 & 14.4 & 16.9 & 25.9 \\
2 & 2 & 6.71 & 6.94 & 11.2 & 14.4 & 17.0 & 25.9 \\
3 & 3 & 6.69 & 6.92 & 11.1 & 14.4 & 16.9 & 25.8 \\
\hline
\end{tabular}


Table 4. Damping Ratio Results under Different Wind Loading.

\begin{tabular}{lllllll}
\hline $\begin{array}{l}\text { Wind Load } \\
\text { Level }\end{array}$ & $\begin{array}{l}\text { Symmetry } \\
\text { First Order } \\
\text { Vertical }\end{array}$ & $\begin{array}{l}\text { Anti-symmetry } \\
\text { First Order } \\
\text { Vertical }\end{array}$ & $\begin{array}{l}\text { Symmetry First } \\
\text { Order Torsional }\end{array}$ & $\begin{array}{l}\text { Anti-symmetry } \\
\text { First Order } \\
\text { Torsional }\end{array}$ & $\begin{array}{l}\text { Second-Order } \\
\text { Vertical }\end{array}$ \\
\hline left & right & $(\mathrm{Hz})$ & $(\mathrm{Hz})$ & $(\mathrm{Hz})$ & $(\mathrm{Hz})$ & $(\mathrm{Hz})$ \\
\hline 0 & 0 & $0.40 \%$ & $0.45 \%$ & $0.87 \%$ & $1.30 \%$ & $0.78 \%$ \\
1 & 1 & $0.55 \%$ & $0.71 \%$ & $0.84 \%$ & $1.40 \%$ & $0.92 \%$ \\
2 & 2 & $0.52 \%$ & $0.78 \%$ & $0.83 \%$ & $1.40 \%$ & $0.82 \%$ \\
3 & 3 & $0.72 \%$ & $0.81 \%$ & $0.87 \%$ & $1.20 \%$ & $1.1 \%$ \\
\hline
\end{tabular}

In addition, it can be speculated that higher ambient excitation is beneficial to modal parameters identification and has higher reliability. From the comparison of SV spectrum under no wind condition and level three wind condition (figure 8), random stimulation would help cover fixed environment factor, such as the $25 \mathrm{~Hz}$ floor-slab incentive.
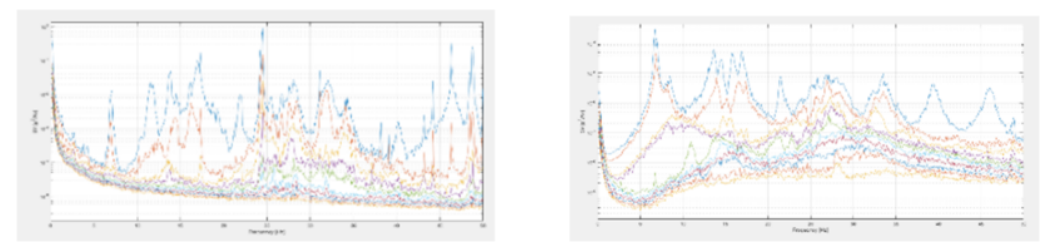

Figure 8. SV Spectrums under No Wind Condition (Left) and Level 3 Wind Condition (Right)

\subsection{Modal Behavior under Different Structure Damage}

Under different structure damage conditions, a distinct structure modal response is observed. Since the damage lowers the structure stiffness and has little effect on the mass, the frequency result is lower than the original structure as expected [9]. The results are summarized in table 5. The experiments show that deficiency of bolts would have a more severe effect in reducing the stiffness than lacking a U-shape connection member. Moreover, in cases with bolts missing, mode shapes become more complicated, and coupled situation takes place of pure vertical or torsional vibration in higher order. However, in cases with U-shape connection members missing, mode shapes are similar to the original response, and only the damaged joint has unusual behavior.

Table 5. Frequency Results under Different Structure Damage.

\begin{tabular}{lllllll}
\hline $\begin{array}{l}\text { Structure } \\
\text { Damage } \\
\begin{array}{l}\text { Type at Mid } \\
\text { Span }\end{array}\end{array}$ & $\begin{array}{l}\text { Symmetry } \\
\text { First Order } \\
\text { Vertical } \\
(\mathrm{Hz})\end{array}$ & $\begin{array}{l}\text { Anti-symmetry } \\
\text { First Order } \\
\text { Vertical }(\mathrm{Hz})\end{array}$ & $\begin{array}{l}\text { Horizontal } \\
(\mathrm{Hz})\end{array}$ & $\begin{array}{l}\text { Symmetry } \\
\text { First Order } \\
\text { Torsional } \\
(\mathrm{Hz})\end{array}$ & $\begin{array}{l}\text { Anti-symmetry } \\
\text { First Order } \\
\text { Torsional }(\mathrm{Hz})\end{array}$ & $\begin{array}{l}\text { Second- } \\
\text { Order } \\
\text { Vertical } \\
(\mathrm{Hz})\end{array}$ \\
\hline Original & 6.75 & 6.94 & 11.1 & 14.4 & 16.9 & 25.8 \\
w/o one bolt & 6.65 & 6.88 & 8.97 & 13.7 & 16.6 & 22.6 \\
$\begin{array}{l}\text { w/o two bolts } \\
\text { w/o U }\end{array}$ & 6.65 & 6.78 & 9.01 & 13.7 & 16.7 & 22.9 \\
connection & 6.72 & 6.93 & 10.2 & 14.2 & 16.8 & 22.0 \\
\hline
\end{tabular}




\subsection{Limitation of Theoretical and Experimental Results}

Though the results from theoretical finite element analysis and experimental model tests have consistency and rationality, they both have limitations to a certain extent. For the finite element model, though the section and material parameter have been input accurately, the particular type and size of bolt connection are complex to be simulated in the software. Elements are assumed to be connected fixed in all directions without a degree of freedom, which is the ideal case for the structure but impossible to achieve. For the experimental model, the material and drilling holes are manufactured and processed by factories so that the work precision cannot be proved. During the assembly process, it is observed that the size and position of the hole do not fit in well as predicted. As a result, the structure would have inappropriate vertical displacement under static conditions. Pre-camber is introduced to solve the problem, which is also not included in the theoretical model.

\section{Conclusion}

This paper introduces the Bayesian FFT algorithm and applies it to deal with multiple close mode identification in modal analysis of the simplified Dongying Yellow River Highway Bridge. Experiments under various ambient excitation conditions and with typical structure damages are conducted. The results of modal parameters meet the expectation well, which demonstrates the reliability and feasibility of the algorithm. Based on the comparison between the theoretical and experimental results, the difference is within a reasonable fluctuation, so that further simulation in the laboratory could be replaced by computer tests with appropriate adaptive treatment, which may have possible use in damage identification for large-scale structures [10].

\section{References}

[1] Zhang XD, Yao QF, Liu P. Research on recognition method of mode shape based on fast independent component analysis. Vibration and Shock. 2009 Jul; 07: 158-161.

[2] Li BB, Kui SA. An expectation-maximization algorithm for Bayesian operational modal analysis with multiple (possibly close) modes. Mechanical Systems and Signal Processing. 2019 Oct; 132: 490-511.

[3] Spencer BF, Nagarajaiah S. State of the art of structural control. Journal of Structural Engineering. 2003 July; 129(7): 845-856.

[4] Brillinger DR. Time series: data analysis and theory. Philadelphia: SIAM. 2001 Sep.

[5] Au SK. Operational Modal Analysis. Singapore: Springer; 2017. p. 265.

[6] Li AQ, Ding YL, Wang H. Analysis and evaluation of massive data of bridge health monitoring: Progress of "structural health monitoring". Science in China: Technology Science. 2012 Aug; 08: 972-984.

[7] Ntotsios E, Papadimitriou C, Panetsos P, et al. Bridge health monitoring system based on vibration measurements. Bulletin of Earthquake Engineering. 2008 July; 7(2): 469-483.

[8] Au SK, Zhang FL, Ni YC. Bayesian operational modal analysis: Theory, computation, practice. Computers \& Structures. 2013 Sept; 126: 3-14.

[9] Xie YL, Li BB, Guo J. Application of expectation maximization bayesian modal recognition algorithm in operation modal analysis of sea-crossing cable-stayed bridge. Journal of Zhejiang University-Science A (Applied Physics \& Engineering). 2020 Jul; 21(07): 553-564.

[10] Yuen KV, Katafygiotis LS. Bayesian Fast Fourier Transform Approach for Modal Updating Using Ambient Data. Advances in Structural Engineering. 2003 May; 6(2): 81-95. 